Lisa Andersen

Faculty of Arts \& Social Sciences

University of Technology, Sydney, New South Wales

PO Box 123

Broadway NSW 2007

lisa.andersen@uts.edu.au

Ph: +61 295142900

Fax: +61 295142911 


\title{
Magic Light, Silver City: the business of culture in Broken Hill
}

\begin{abstract}
This article examines cultural industries in Broken Hill—-the iconic 'Silver City' of Australian mining in far western NSW - and comes from research funded by arts and regional development agencies during 2006 and 2007. In interviewing and surveying the 'movers and makers' of the local cultural sector a picture emerged of a successful group of mainly informally qualified professional visual artists and crafts people working from home studios who spend more time on their practice and make more money than their metropolitan counterparts; a thriving service sector, fine weather and competitive location infrastructure for screen industries; and a community proud of its 'arid artists' and its historical and international reputation as a film set. Artists enjoy the lower-than-city costs of accommodation, the quality of light, their proximity to 'Outback' and industrial landscapes, and sustainable local and seasonal tourist markets. With a focus on richly coloured landscape painting and traditional crafts and some contempt for the city 'art mafia', there is limited diversity of cultural products and a 'half-Sydney' market ceiling price on local sales. The Indigenous arts sector has a low profile and is surprisingly_ given high numbers of international touristsunderdeveloped. The arts community is fragmented by divisions that both reflect the male-dominated, rugged independence and 'us and them' heritage of this desert mining and 'union town' and inhibit cooperative development. Remoteness means wariness of newcomers and new ideas; young people leave; limited access to business expertise, production services and training; and high transport costs. Isolation means a unique local culture; a friendly community; freedom from city-based art fads, stress and busyness; and blue skies, time and a clear view.
\end{abstract}

\section{Key Words}

Broken Hill, regional Australia, remote arts, creative workers, cultural industries, film location, mining towns 


\section{Introduction}

Imagine a place completely burnt up, not a green leaf or blade of grass, not a particle of shelter, and the heat of the sun about 170 degrees; add to this dust such as I never experienced (enveloping the place like fog), and you may perhaps realise my position in having to sketch in the open. Must also tell you that the ground was so terribly hot that all the time I had to keep picking my feet up, for it felt like standing on hot coals.

Brothers of this Brush in England, how would you like to sketch under these conditions?

From an 1888 letter by artist Edmund Harral, Broken Hill Historical Society

I strongly believe this is the artistic capital of — not just Australia—-the Southern Hemisphere.

Interview with a Broken Hill artist, 2007

This article discusses cultural industries in and around Broken Hill in far western NSW and stems from research undertaken in 2006 and 2007 through the Far Western Regional Development Board, NSW Department of State and Regional Development, Regional Arts NSW and West Darling Arts. Here I draw on findings of that research project to address the specific themes of this special issue - the impacts of remoteness and isolation on creative making.

Located on the semi-arid Barrier Ranges - traditional country of the Wiljakali people - the City of Broken Hill has a population of 20,210 (ABS 2008), observes Central Standard Time, and is 1166 kilometres from Sydney. The history of 'Silver City', as Broken Hill is sometimes called, has been dominated by the mining of one of the world's largest deposits of silver, lead and zinc. The surrounding region consists of large properties and small, isolated communities connected by sealed and unsealed roads. The city is a regional centre for the 16-million hectare, West Darling pastoral industry and the surrounding towns of Menindee, Tibooburra, White Cliffs and Wilcannia

Mining began in 1883 with the first lease on the Line of Lode-marked by a 'broken hill' noted by Charles Sturt in 1844 — and the Broken Hill Proprietary Company (BHP) was incorporated in 1885. The 1933 Census recorded Broken Hill with 26,975 residents, the third largest urban population in NSW behind Sydney and Newcastle. The insularity, 'rugged independence', 'making do' and 'make our own fun' characteristics of extreme remoteness - water was carted to the city until the opening of a pipeline from Menindee after World War II—combined with the technical skills and tools of the mining industry and what Julaine Allan described in 2008 as 'mining's relocation culture' have had a dominating influence on social memory and cultural practice. Alongside this is the powerful heritage of the local labour movement, as noted in the Broken Hill City Council's 2005 Cultural Plan:

Mining and the related trade unionism have been central to Broken Hill's culture and have influenced all aspects of life in the City. Apart from the specific impacts of unionism... relationships between members of the community, trade unionism and socialism spawned many of Broken Hill's 
cultural icons.

It has been a town where:

civic and community affairs have been dominated by workers and their unions... where workers... achieved a degree of collective control unparalleled in Australian historical experience. (Ellem \& Shields 2000, p.116)

It led to the establishment of NSW's first regional art gallery in 1904, followed in 1907 by the first regional public library.

There is a strong local feeling of 'us and them' in Broken Hill. It has an accompanying terminology-if locally born you are an 'A-grouper', if you marry a local you qualify as 'B-grouper', and all others are from 'Away'.

From the 1940s onwards the population of miners slowly began to fall due to declining mineral stocks, changes in demand and increasing industry automation and by the 1970s the Line of Lode was no longer the most important mining field in Australia. For the past 30 years global zinc prices have driven boom and bust cycles in the local economy-currently in downturn during the Global Financial Crisis with mine closure and the loss of 440 local jobs in mid-2008.

Heritage and Outback tourism has become increasingly important for the local economy and - with 18.5 percent of the population over 65 (ABS 2008)—social services for a 'retirement town'. The regular turnover of health, mining and education professionals from Away, who leave with a 'souvenir' of their time in Broken Hill, and the growing number of tourists-currently around 9,000 international and 140,000 domestic overnight visitors per year (Tourism Research Australia 2008, p.1) — created a market for local arts and crafts. In the past forty years the arts and cultural sector has played an important role in income generation, location appeal, entertainment, heritage and the creation of local cultural identity.

Locally born arts identities who left to pursue their practice elsewhere include: actor Chips Rafferty, who returned to make his last film, Wake In Fright, in the region in 1971; singer June Bronhill, who took her stage name from the town; comedian and author Steve Abbott, aka The Sandman; and musician 'Lord' Tim Grose, who formed the heavy metal band Dungeon in Broken Hill before heading to Sydney. But visual artists, including Pro Hart, Jack Absalom, Badger Bates and Albert Woodroffe, have been more inclined to stick around and this is reflected in the demographics of local arts practice. Pro Hart was one of Australia's most popular and commercially successful visual artists and sculptors and he lived in the Far West all his life. This former miner and famously self-taught and self-promoting artist-who felt the 'art mafia' never accepted him as a 'proper' painter-developed a hobby into international reputation from the 1960s, painting the region with a richly coloured, naïve style. Germaine Greer, writing in The Guardian in 2006, described his landscapes as

not just illustrations of outback life: they glow with the unforgettable light of the inland. His gangling twisted feather-top trees are portraits of the acacias and casuarinas that refract the raking sun of the desert edge in a luminous haze... The syncopation in the replication of their gnarly boles is the genuine 
rhythm of the Murray-Darling.

During the 1970s, Pro Hart and fellow Broken Hill artists, Jack Absalom, Eric Minchin, John Pickup and Hugh Schulz-a group that emerged from the hobbyist Willyama Art Society_-formed the 'Brushmen of the Bush' and collaborated on more than fifty Australian and international exhibitions from 1973, establishing a reputation for Broken Hill as a centre for 'Outback art' and arid landscape painting. Interviewed in The Sydney Morning Herald of 26 May 2006, John Pickup said,

We wanted to show the rest of the world what life in our home town was like. The quality of the light. The magnificence of the country. And the unbelievable colours of the soil.

On his death in 2006, Pro Hart was awarded the first state funeral for a visual artist and the first held in western New South Wales.

The passing of Broken Hill's best known resident gave rise to a sense in some that the local arts community was declining and ageing. West Darling Arts and the Far Western Regional Development Board initiated a research project to gain a better understanding of the 'state of the arts' in Broken Hill and to assist in improving the business climate for local cultural industries. The research describes a confident, growing sector of older artists who earn more income and have more time to work on creative practices than their metropolitan counterparts. The report made 51 recommendations for developing the sector and increasing community engagement, including a professional artist network, a market development agency, mentoring and apprenticeship programs for young people, greater visibility for Indigenous arts, and the establishment of a film museum in the town (See Andersen \& Andrews 2007).

\section{Method}

While understanding that creative making - particularly in rural and remote regionswill range along a non-profit to for-profit continuum of activities, the research was specifically concerned with 'practising', 'professional' 'creative' practitioners living in the region. As Throsby and Hollister have noted:

The practising aspect means that we confine our attention to artists currently working or seeking to work in their chosen occupation. The term professional is intended to indicate a degree of training, experience or talent and a manner of working that qualify artists to have their work judged against the highest professional standards of the relevant occupation. (2003, p.14, my italics)

For the Australian Bureau of Statistics:

Professional creative participants are broadly defined as creative participants who have a serious commitment to their arts practice and consider it a major aspect of their working life, regardless of their income or employment status. (2006, p.6, my italics)

During the cultural audit phase, categories of creative practice and support roles of specific interest in Broken Hill were identified as: 
1. Visual arts, craft and design

2. Music and performing arts

3. Traditional and Indigenous practice

4. Writing and communication

5. Community cultural development

6. Support roles - teachers, cultural managers, screen industry services, production suppliers and arts retailers

The project was launched by the local Member of Parliament at Broken Hill Regional Art Gallery and achieved extensive local media coverage. To build trust, the Far Western Regional Development Board also widely distributed a newsletter that introduced the researchers. A Research Advisory Group-made up of artists, arts business owners, arts support workers, local, federal and state government officers, and community development workers-was consulted throughout the project. To ensure that some long-standing divisions within the local arts sector did not negatively impact on the research, members were asked to encourage their friends and colleagues to participate.

Existing information proved surprisingly difficult to identify and source, and was often not locatable. The main issues were: information on projects or programs were not recorded and there was an absence of tracking and evaluation processes; significant losses of community knowledge and momentum when people 'moved on'; and the politics of previous projects, where lack of action taken, factionalism or disagreements, or a sense of failure lead to an unwillingness to record information and a desire to 'forget'. This may be a generic issue for researchers working on cultural industries in small and remote places (See Lea et al 2009). One community development worker observed that:

A lot of ideas in Broken Hill seem to stall - they get to a certain point and then don't go any further. Sometimes it is because the people who have been part of development and championing leave and the idea just stops. Sometimes the message you get... as soon as you say that 'I have got this idea' is 'they tried it elsewhere and it failed'... Because other projects have failed I don't think it's a reason to stop all projects-you need to learn from the mistakes and not make them again.

A cultural audit was completed-including searches of telephone books, tourism literature and the web, recommendations from cultural managers and artists, and observations from 'walking the streets' - and a database (now housed with West Darling Arts) of local professional and emerging artists, cultural businesses and relevant support services was developed. In addition, the researchers spent two days trailing through private galleries, souvenir retail outlets, cultural and Indigenous infrastructure and tourism information distribution points to count infrastructure, examine the range of products for sale and audit public (in particular, tourism) information on the local arts sector.

A 21 page, self-completion questionnaire was posted to artists, arts businesses and cultural workers listed on the database and questionnaires were also hand delivered by the Regional Arts Development Officer, James Giddey. Forty five completed questionnaires were returned. The survey took approximately one hour to complete 
and, while it is very likely that some people would have had difficulty filling it in, the response rate was positively affected by the survey being distributed three weeks after the 2006 Census of Population and Housing, another complex instrument.

To enable national comparisons, creative practice categories and questions on income, employment, training, funding and career highlights were taken from Throsby and Hollister's 2003 survey of Australian professional artists. Cathy Henkel's questionnaire for her 2006 analysis of the screen industries in the NSW Northern Rivers region was also referenced. Follow-up interviews, strategic conversations and focus groups were conducted with 41 people.

\section{Cultural Infrastructure in Broken Hill}

From the 'Roaring days' of mining there are a large number of local hobbyist and amateur cultural organisations, some dating back more than 50 years that now have an ageing and declining membership. They include the Willyama Art Society, the Broken Hill Philharmonic Society, the Repertory Society, the Inland China Painters, Poets in the Pub, the Cameron Pipe Band and the Barrier Industrial Union Band. The 'professional' cultural organisations-publicly funded to (amongst other things) act for development and create the potential for new activity-include Broken Hill Regional Gallery, West Darling Arts, Broken Hill Art Exchange, Broken Hill Library and the Writers Centre.

The Indigenous arts sector has a low profile and is surprisingly—given high numbers of international tourists - underdeveloped. However, there is a recognised Barkindji art 'style' from the Central Darling region associated with the work of Badger Bates, Phillip Bates and Murray Butcher (Gibson 2008) and West Darling Arts has a specific focus on developing Indigenous arts and crafts. In 2008 the Broken Hill Regional Art Gallery introduced the Far West Emerging Aboriginal and Torres Strait Islander Art Prize to encourage emerging artists within the region.

The first private art gallery in Broken Hill was opened in 1972 and there are between 25 to 30 private galleries in Broken Hill and Silverton. The galleries range in character from retail outlets with regular opening hours showcasing a number of local and other artists, such as the Silver City Mint and the Horizon Galleries; to smaller galleries in private houses around suburban Broken Hill focusing on the work of one or two artists, such as Boris Hlavica's Photographic Gallery; to showrooms in artist studios, such as Deidre Edwards' studio and framing workshop; to unique spaces such as Thankakali Gallery, in the cellars of an old brewery building, and the John Dynon Gallery in an 'authentic outback dwelling' in Silverton.

The so-called 'ghost town' of Silverton, 25 kilometres northwest of Broken Hill, is an important local centre for the production and sales of art. The current tiny population of around 50 includes a number of visual artists and four galleries selling locally created art and craft. Silverton has also been a vital component of the region's attractiveness and development as both a film location and tourism destination. The 'magic light', the high number of clear filming days, the desert landscape and the industrial infrastructure are also reasons for the region's success as a film location. Since the 1960s more than 20 feature films and 200 commercials have been filmed locally. Mad Max 2, The Road Warrior (1981) and The Adventures of Priscilla, 
Queen of the Desert (1994) are the best known and are heavily promoted in tourism literature. As a screen worker commented, 'Mad Max 2 was filmed here 25 years ago and people are still coming to find it'. Film crews also praise the 'can do' attitude of the locals and the fact that they tend to leave film visitors alone 'to get on with it'. One screen worker remembered that:

Mel Gibson said, when he was out here filming Mad Max 2, that there were 30 to 40 people coming out to watch the car stunts, but they never approached him for an autograph, they just sat and watched the cars rolling. On one of the last days of filming he actually went over to this group and said 'You've been watching it all?' and they were like, 'Yeah, gidday Mel.' 'How are you?' 'Love the movie!' and then one boy stood up and asked him for an autograph. Five weeks of filming: one autograph.

The community may not be 'rubbernecking' but are excited by the film work and are helpful to productions. As another screen worker said, 'When there is a film crew in town there is a buzz about and everyone in Broken Hill wants to be an extra'.

Another unique cultural and tourist location is the Sculpture Symposium on Sundown Hill in The Living Desert Reserve where, in 1993, visiting and local sculptors worked with sandstone from nearby Wilcannia to create their sculptures.

\section{Who are the artists of the Far West?}

Visual artists, craft practitioners and designers make up more than half (51 percent) of professional creative workers in the region. Other occupations include musicians, screen workers, writers, community-based artists and cultural managers. Two thirds of practitioners work in specialist areas, including basket maker, photographer, cartoonist, casting director, circus trainer, fractal imaging, graphic designer, sculptor, jeweller, short story writer, wood worker, restorer and stockwhip maker. Thirty eight percent are 'established' practitioners who have been working in their creative occupation for longer than 21 years and 31 percent are 'emerging' and have been practising 5 years or less (See Figure 1).

The two groups have different professional and business development needs, with established practitioners more likely to need support using new technologies for business efficiency and the emerging group more focused on developing practice skills and establishing a business. Emerging and mid-career artists expressed a desire to learn from successful older artists - 'they have a lot to teach us'. Seventy one percent of artists are older than 45-with 40 percent older than 55-and qualitative research showed that even artists who move to the region are often older, more established artists with existing markets who relocate for both economic and lifestyle reasons. One interviewee remembered that:

I fell in love with Broken Hill, with the desert, when I was out here shooting a car ad, then again for a [magazine] shoot... then I saw an ad in the paper so I came out and now I've got a house and everything.

Another said that: 
I brought my market with me. I send my work to established outlets elsewhere... I have a network of galleries around the country... And I don't think that artists do actually retire. You paint 'til your hands give out.

Only eighteen percent of artists were younger than 35 and only one artist was younger than 25. The qualitative research told a story of younger artists leaving the region for Adelaide or Sydney to access professional skills, markets and 'more exciting' lifestyles.

Artists were asked to breakdown the time they spent working (See Figure 2) and to itemise their annual income from July 2005 to June 2006 into money received from (1) their creative practice, (2) arts-related income (such as teaching and arts administration), and (3) income from work not connected with the arts. The average earned annual income from all work was $\$ 44,331-$ with the median $\$ 45,000$. This was higher than the average earned income in Broken Hill of \$36,834 (ABS 2008). Average annual income from creative work alone was $\$ 22,497$; which compares favourably with the national figure for professional artists where the average income from creative work is $\$ 17,000$ (Throsby \& Hollister 2003).

Only 25 percent of creative makers had specialist arts qualifications and, at the time of the survey, only 11 percent were undertaking any form of training, either formal or informal. Overall results indicate lower local levels of formal and specialist qualifications than found in the national profile artists (See Throsby \& Hollister 2003). TAFE certificates are the most common formal qualifications. In keeping with a tradition established by the Brushmen of the Bush, 62 percent of artists described themselves as 'self-taught' and half had learned 'on the job'. Nearly half had also accumulated skills through workshops or short courses, 38 percent had received training or work experience through a private teacher or practicing professional and 13 percent had been mentored. Not surprisingly, when asked to specify additional training needs the most common response was a desire to participate in arts exchanges with successful artists, both local and from 'Away'.

Local practitioners also have very low levels of membership of professional organisations and associations. 11 percent were members of the National Association for the Visual Arts (NAVA) and 13 percent were members of local organisations, including the Willyama Art Society and Broken Hill Regional Art Gallery. Focus groups reiterated a general lack of knowledge about the professional organisations and specialist arts support agencies of metropolitan Australia.

\section{The Business of Art}

Most artists in Broken Hill are sole traders (36 percent) or in a partnership arrangement (21 percent). Eleven percent are companies and 16 percent are employed by someone else's business. Other business structures used are incorporated associations and family trusts. The 26 small businesses that participated in the survey currently employ a total of 77 people, including owner/s, full-time and part-time staff; an average of three per business. Less than half (42 percent) are being guided by a business plan in their creative business and only 41 percent have ever received professional business advice. 
The average annual marketing spend was $\$ 3818$, or 17 percent of total income earned from creative practice. While 77 percent of artists are primarily responsible for promoting their creative work and developing markets, only 31 percent of respondents have a marketing plan in place. The main venues or outlets used to display or sell work services are, in order: private galleries and venues, repeat customers, commissions and through exhibitions or performances in public venues. While most (but not all) artists use computers and the internet in research, creative work and office and administration work, only 36 percent used computers for recording and tracking clients or artworks on consignment and only 11 percent used e-commerce.

Arts businesses are aware that they need to spend more time and resources on building markets and outlets for their work but, while most understand the local market very well, the distance — both geographical and psychological—-to 'outside markets' is vast. They also see that they need to share knowledge more often and cooperate to build audiences outside the region—so they are less dependent on seasonal tourist sales - and to promote the brand of Broken Hill as an 'arts place'. But factionalism, long-standing divisions, and professional rivalries hinder cooperative effort.

Creative businesses are optimistic about future prospects; 36 percent described their businesses as 'growing' over the next three years, 38 percent as 'sustainable', 17 percent as 'commencing' with only 9 percent describing their businesses 'in decline'.

\section{Arts Markets}

Local consumption is the largest part of the market with local residents responsible for 39 percent of total sales and tourists accounting for 30 percent (See Figure 3). There are a number of serious local collectors of Broken Hill art and established visual artists observed there is more interest from this group in when an artist is 'starting up', or that the collectors 'keep an eye out to get in on the beginning of something-when you start something new'. However, local purchases were characterised as: for family presents and interior decoration; gifts for someone leaving town from work colleagues (such as a mine worker, teacher or 'visiting medico'); and people who are leaving town purchasing a 'memento' of their time in the Far West (again, usually professional mining, education and health workers). One artist said: 'When they [people who have been working in the region] do the big house sell-off when they leave town, they go around and buy up what they like, and they spend big-it's a keepsake'. A well-established visual artist commented that he had developed two distinct styles of work: one that fitted the interior design market and the other for commissioned works, commonly paintings of mines bought by or for people who had been working in that sector.

The tourism market is seasonal and local buyers sustain the artists throughout the low and shoulder tourist seasons. As one artist described this situation: 'December to March are pasta and salad days, but when April comes, with the tourists, it means steak for dinner'. Artists also talked about a price ceiling for local sales, which one artist described as 'around $\$ 3,500$, which is difficult to get above. The same painting if sold in Sydney would fetch a price of $\$ 9,000$ '. Visitors with more outwardly visible discretionary income are (not surprisingly) more likely to purchase 'big ticket' 
artworks. One artist talked about, 'the Subaru Forrester drivers, who, when you see them pull into the car park, you know will leave with something from our gallery'. Other likely purchasers of outback artworks are visitors on long tours who use Broken Hill as an entry and exit point for travels in the Outback and buy artwork as a memento of their trip on their return journey.

The US and Europe account for most international sales. Sales to international visitors need to be 'crated and freighted' which affects the sale price. 'When you box it up and give them a price', one artists commented, 'they go "oh my god!"--TNT is like \$150 for a painting'.

\section{Life in the West - place and practice}

One third of creative workers were born in the Far West and 20 percent have lived in the area for more than 20 years. Of the locally born artists, a number had moved away for many years to travel and establish careers, and then returned. One interviewee spoke about being asked why they had moved back to Broken Hill:

Not all of them [local people] understand it. They're usually from the mines, and their idea of the place has been entrenched because of their work. They don't see the artistic side. Also, some people live here and don't get the opportunity to see different places and experience other things, to compare. I was born here and then moved back, so I'm an A-grader. My friends, a couple of them were artists from Broken Hill who went out to explore the world, then came back for the isolation and stuff.

Twenty seven percent of artists had moved to the area in the past five years. 'Five years', said one:

that's sort of the milestone in Broken Hill. I've seen lots of very talented and productive artists move away. Could be many reasons. Maybe people aren't ready for their work, like they're not mainstream or landscape artists... I think they should stay because new stuff brings change... I dunno, maybe they're sick of banging their heads against the wall.

Many had previously visited and 'fallen in love' with the landscape and/or the 'magic light' and/or the sense of 'freedom', but had made the decision to move to Broken Hill to have more time to spend on their arts practice and because housing and studio spaces are 'cheap'. During a focus group one artist said:

I was going to live in Spain, but we had to wait two months until our daughter was born so I thought I'd travel around Australia. And I came across Broken Hill three times in all that. It was the friendliness, the lighting, the colours. Just the whole environment. It was almost like a magnet, bringing me back here.

Another commented: 'I moved here to get on with artistic endeavours in my life but I've taken a real liking to it... I had been here before...[and] I wanted the space and community, the freedom'. Yet another said that in Broken Hill they could have: 'A house for ourselves, for $\$ 50000$, out the back of a gallery. I have my own gallery and four bedroom house out the back of it. It's perfect'. Another sub-group are people 
'escaping' some trouble in their life who see Broken Hill as a 'fresh start'.

Figure 4 shows the top ranked disadvantages for creative making in the Far West. Alongside feelings of isolation and lack of local resources there was also a sense of the insulation of the local community and the lack of 'cultural stimulation' including a lack of access to cultural events, fellow artists and being able to 'keep up with what is going on in the cities'. Twenty four percent of artists also felt that the region placed 'too much emphasis on landscape art'. The cost of materials and the availability of local suppliers was also a concern. (A somewhat despondent artist wrote across the questionnaire, 'Unfortunately I had only five choices, otherwise I would have probably chosen nearly all of them'.) However, the vast majority of artists (84 percent) felt that living outside of a capital city had had a mainly positive impact on their practice. The inspiration of the landscape and the visual environment were the most important positives for creative practice followed by the lower cost of living (See Figure 5). As a sub group, traditional and craft practitioners talked about the access to local, raw materials and the 'genuine' quality of their work. Other advantages were: enhancement of personal health (31 percent), less crime (24 percent) and less competition (18 percent). A large number of artists contrasted the 'freedom' of their life in the West with their perception of the 'stress' of a Sydneybased artist's lifestyle:

I spent three months recently in Sydney and I didn't pick up a pencil or a brush the whole time. I was too busy and stressed. I have more choices here, to relax more and paint. In Sydney there's a pressure to have a different lifestyle.

(interview 2007)

Similarly, another artist commented:

This is what I sense from people in Sydney, I mean, they talk about the brightness of our colours and sculptures. Whereas Sydney I find very oppressive. I think there's a real sense of creativity in this community, a kind of feeling or vibe.

Artists who had moved to the region described city-based pressures on creative practice to conform to art 'fads and fashions'. As one artist said of his life in Sydney, 'I used to feel as though I had to conform to certain styles, like my creativity was being squashed in a box'.

The desert and mining landscapes and the quality of local light exerted a powerful influence on every artist I spoke to and a number of them are active in environmental causes. 'It's very uplifting', one commented,

I find as I'm driving home to Broken Hill I can feel it. You leave all that stress behind and get a new perspective. I find it very stimulating. I think there's a physical thing too. Of clarity. Like the view from the window. You look out and everything's so clear. I've been to many other countries... and I haven't found a clearer view. The vivid blue sky, the sharpness of the landscape, and the variety.

Artists who had painted the Outback for many years described a deep psychological connection with the desert landscape. One artist said that, after years of painting the drought, she dreams of deep underground pools of water and had even developed a 
new, painting style around deep blues and greens-'not that there is a market for that work out here. People come here to buy Outback art'. One artist wrote that, 'Art making in context of desert rather than more lush conditions provides a timeless context'.

\section{Conclusion}

The Broken Hill research reveals that life on the periphery is both enabling and disabling for artists. The Arid Arts and Crafts community of Broken Hill—as well as the Santa Fe Art Colony, the Småland glass designers of southern Sweden, and the Blue Ridge Mountain craft makers of North Carolina - are good examples of how creative practitioners can use their 'remoteness', wild landscapes, and local culture, traditions and materials in making and marketing unique creative products that successfully tap into consumer's imaginations. But more research is needed to develop a better understanding of creative practice in remote communities, the impacts of peripherality on the individual makers who are the source of wealth for this sector, and the opportunities of the evolving information economy. In Broken Hill, 'Remoteness' means limited types of creative making; wariness of newcomers and new ideas; the loss of young people; limited access to business expertise, production services and training; lack of cultural stimulation; and high transport costs. 'Isolation' means a unique local landscape and culture; a friendly community; lower-than-city costs for accommodation and studio space; freedom from city-based art 'fads', stress and busyness; and a 'quality of light', time and a clear view.

\section{Acknowledgements}

This article is based on my research for the Far Western Development Board and West Darling Arts, published as Quality of Light, Quality of Life: professional artists and cultural industries in and around Broken Hill (2007) with funding from the NSW Department of State and Regional Development, Regional Arts NSW and the Australia Council for the Arts. Many thanks to my co-researcher, Jane Andrew. I acknowledge the ideas generated by numerous A-Groupers, B-Groupers, and people from Away who contributed to the research-especially Eileen Braybrook, Ellenor Day, Geoff de Main, Fiona Ellis, James Giddey, Cathy Henkel, Kathy Kennewell, Elizabeth Rogers, Robert Sidford, Grant Smith, Bronwen Standley-Woodroffe, David Throsby and the members of the Research Advisory Group-and thank them for their generosity.

\section{References}

ABS (2006) Arts and Cultural Heritage in Australia. Key Issues for an Information Development Plan-Discussion paper. Australian Bureau of Statistics, Canberra. ABS (2008) 1379.0.55.001-National Regional Profile, Broken Hill, 2002 to 2006. Australian Bureau of Statistics, Canberra.

Allan, J. (2008) Discussion Paper 1, Centre for Inland Health. Mining's Relocation Culture-Implications for family, community and industry. Charles Sturt University, Wagga Wagga.

Andersen, L. and Andrew, J. (2007) Quality of Light, Quality of Life: professional artists and cultural industries in and around Broken Hill. Far Western Regional Development Board, Broken Hill.

Bradon, E. and Shields, J. (2000) Making a 'Union Town': Class, Gender and 
Consumption in Inter-War Broken Hill. Labour History 78, pp. 116-140.

Broken Hill City Council (2004) Cultural Plan 2005-2010.

Broken Hill Historical Society. A Visit to Broken Hill in 1888: Letter from Edmund Harral. Pages and Photos from the Past of Broken Hill at

http://www.geocities.com/bhhsi/, accessed 18 October, 2009.

Far Western Regional Development Board (2003) Strategic Plan 2004-2010.

Greer, G. (2006) Australia's Lowry is finally being recognised by its artistic elite - but is it for the right reasons? The Guardian-8 May.

Haslam McKenzie, F. (2007) DKCRC Report 21. Attracting and retaining skilled and professional staff in remote locations. Desert Knowledge Cooperative Research Centre, Alice Springs.

Henkel, C. (2006) Imagining the Future 2: Screen and Creative Industries in the Northern Rivers region. Northern Rivers Regional Development Board, Lismore. Gibson, L. (2008) 'We don’t do dots-ours is lines': Asserting a Barkindji Style. Oceania, 8:3, pp.280-298.

Lea, T., Luckman, S., Gibson, C., Fitzpatrick, D., Brennan-Horley, C., WilloughbySmith, J. and Hughes, K. (2009) Creative Tropical City: Mapping Darwin's Creative Industries, Charles Darwin University, Darwin

Throsby, D. and Hollister, V. (2003) Don't give up your day job: An Economic Study of Professional Artists in Australia. The Australia Council for the Arts, Sydney. Tourism Research Australia (2008) Tourism Profiles for Local Government Areas in Regional Australia, City of Broken Hill. Tourism Australia, Canberra. 
Figure 1: Length of time working in Primary Creative Occupation

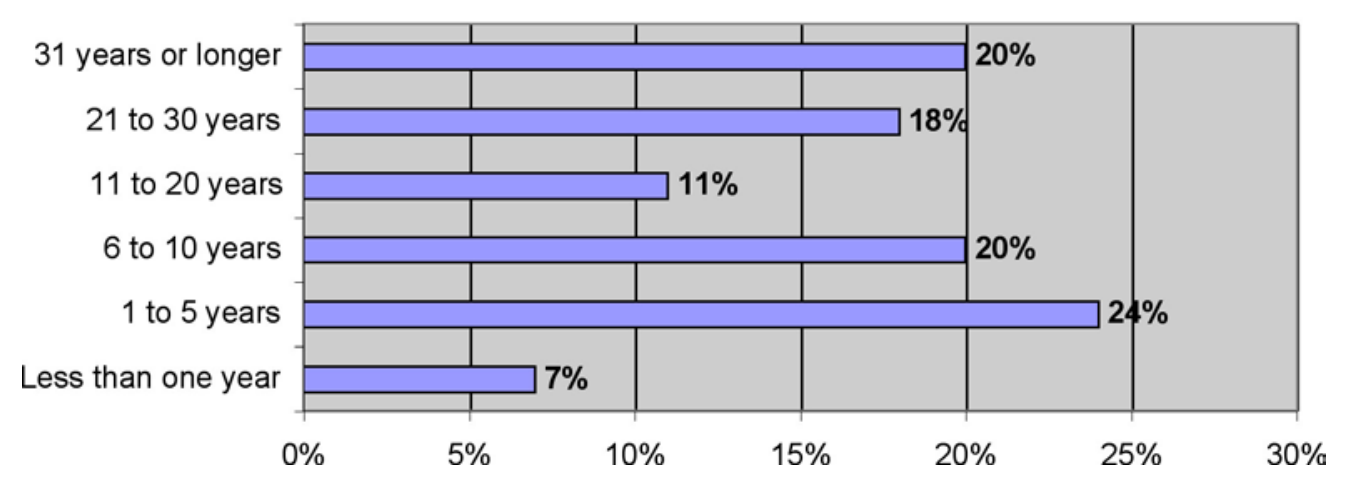

Table for Figure 1

Figure 1: Length of time working in Primary Creative Occupation Percent

Less than one year

$7 \%$

1 to 5 years

$24 \%$

6 to 10 years

$20 \%$

11 to 20 years

$11 \%$

21 to 30 years

$18 \%$

31 years or longer

$20 \%$ 
Figure 2: Division of time spent working, July 2005 to June 2006

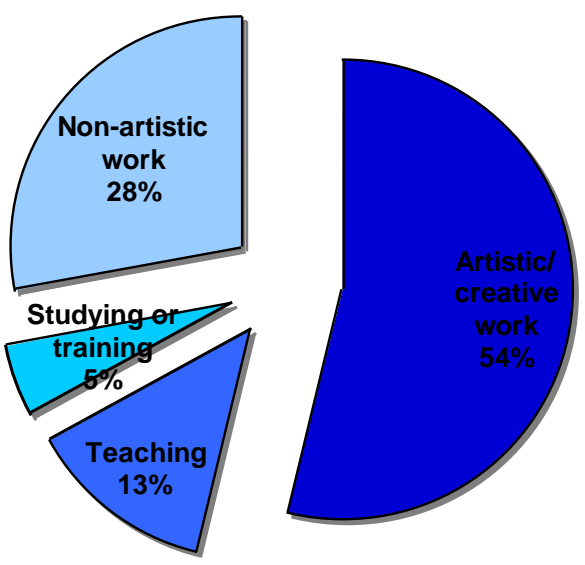

Table for Figure 2

Division of time spent working, July 2005 to June 2006

Percent

Artistic/creative work in your Primary Creative Occupation

$54 \%$

Teaching

$13 \%$

Studying or training in support of your Primary Creative Occupation

$5 \%$

Non-artistic work

$28 \%$ 
Figure 3: Estimated Percentage of Business/Sales by Location

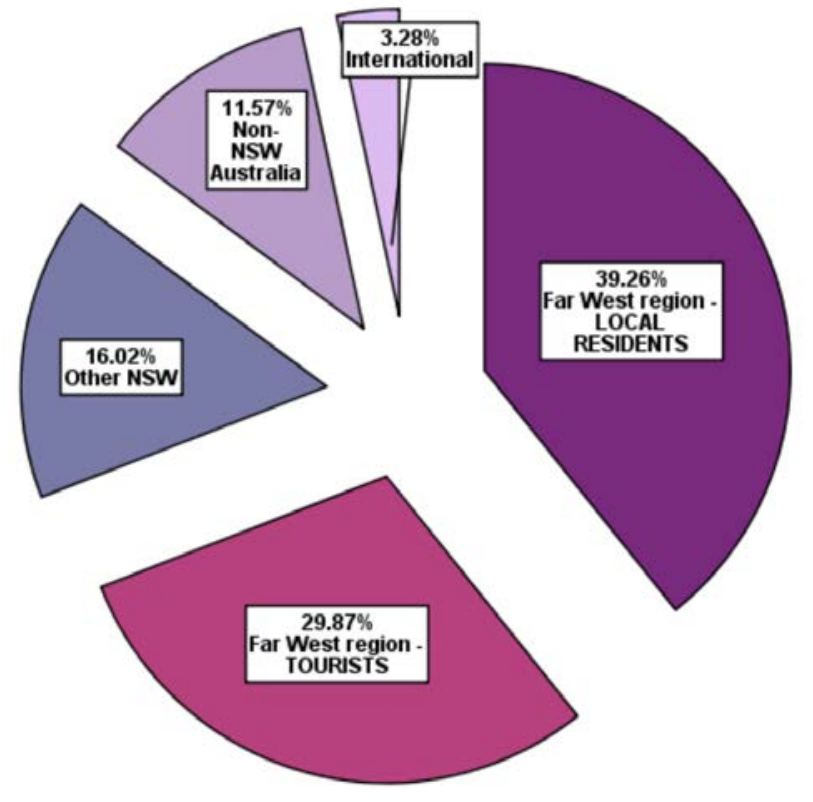

Table for Figure 3

Estimated Percentage of

Business/Sales by Location

Far West region - local residents $\quad 39 \%$

Far West region - tourists $\quad 30 \%$

Other NSW 16\%

Other Australian states/territories $\quad 12 \%$

International $\quad 3 \%$ 
Figure 4: Top Six Disadvantages of Living in the Far West

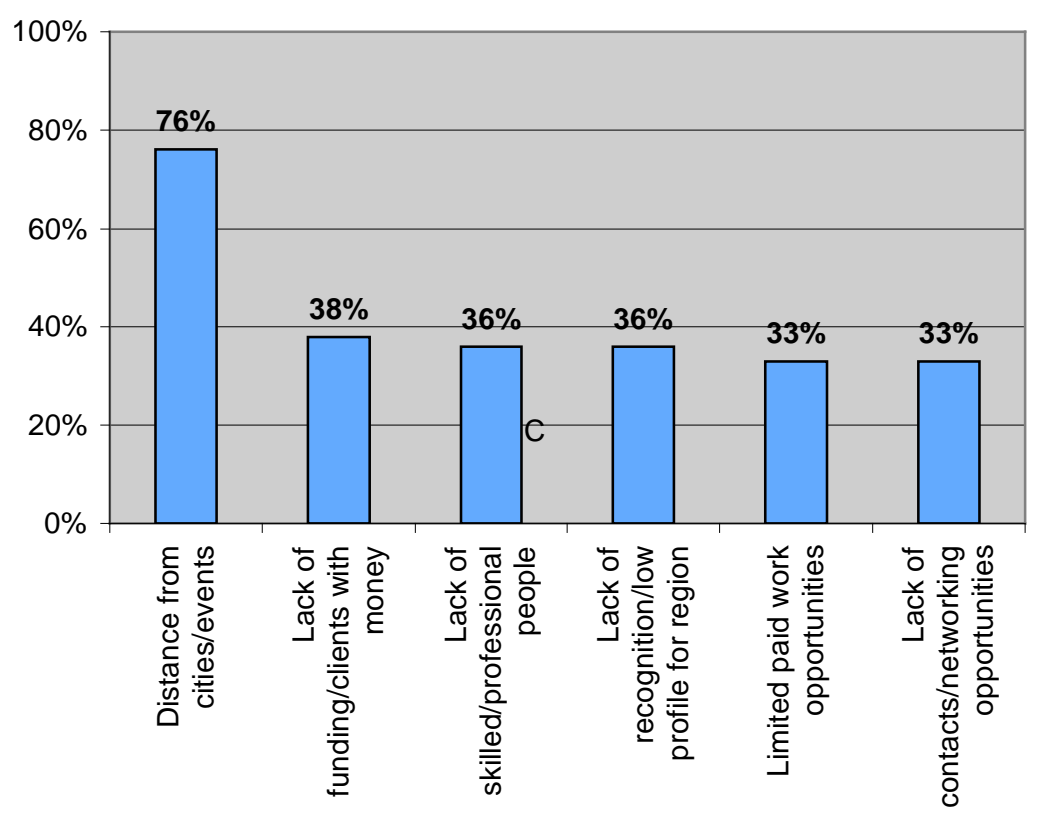

Table for Figure 4

Top Six Disadvantages of Living in the Far West Percent

Distance from cities/events $76 \%$

Lack of funding/clients with money $38 \%$

Lack of skilled/professional people $36 \%$

Lack of recognition/low profile for region $36 \%$

Limited paid work opportunities $33 \%$

Lack of contacts/networking opportunities $33 \%$ 
Figure 5: Top Six Advantages of Living in the Far West

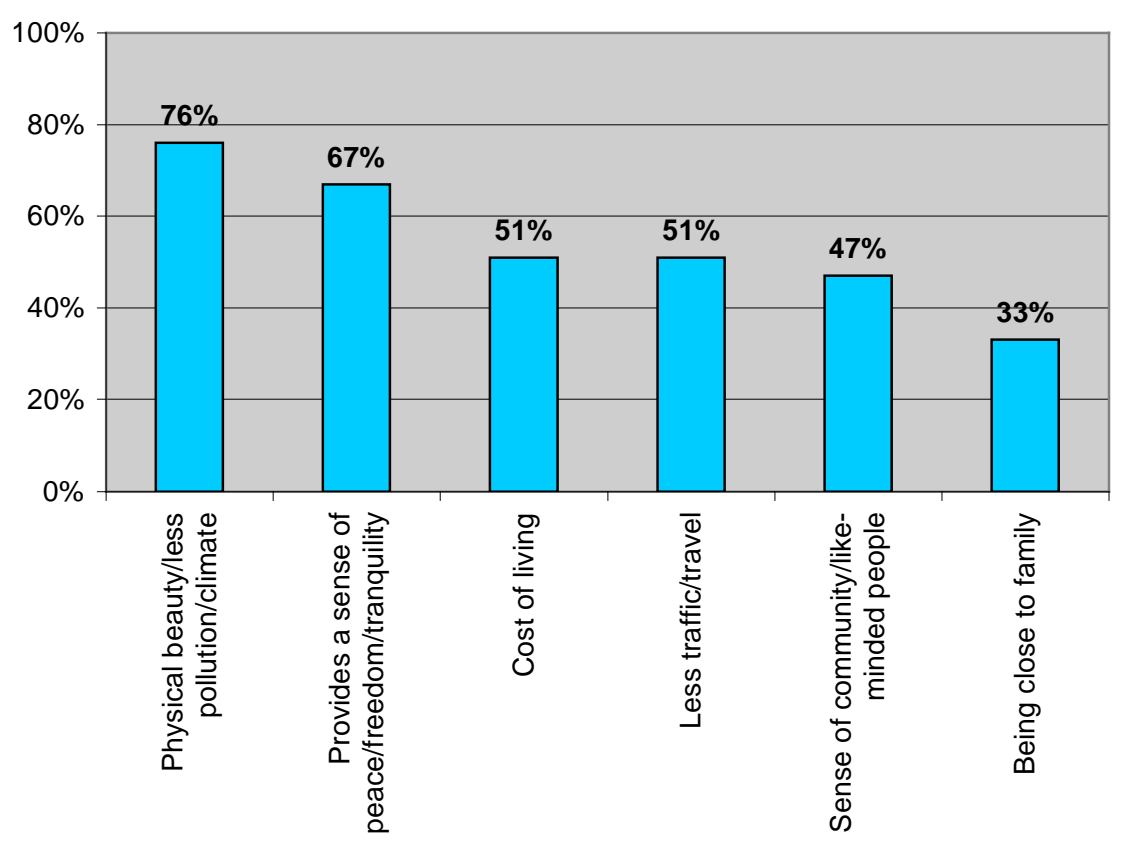

Table for Figure 5

Top Six Advantages of Living in the Far West Percent

Physical beauty/less pollution/climate $\quad 76 \%$

Provides a sense of peace/freedom/tranquility $\quad 67 \%$

Cost of living $\quad 51 \%$

Less traffic/travel $\quad 51 \%$

Sense of community/like-minded people $\quad 47 \%$

Being close to family $\quad 33 \%$ 